\title{
A incorporação do testemunho oral na escrita historiográfica: empecilhos e debates
}

\author{
Maria de Lourdes Monaco Janotti*
}

\section{Alguns pressupostos}

Apesar de rigorosas intervenções metodológicas empregadas por pesquisadores em entrevistas, transcrições e edições, há controvérsias a respeito da natureza de textos produzidos colados à reprodução de transcrições de relatos biográficos. Esses trabalhos são considerados mais adequados à divulgação de experiências de vida de interesse público ou particular, à constituição de acervos arquivísticos, visando ulteriores pesquisas, ou a publicações de interesses privados. Pesquisadores que militam na área de história oral começam agora a questionar a contribuição efetiva que tais escritos possam trazer para o conhecimento histórico.

Testemunhos espontâneos ou provocados possuem implicações teóricas profundas que a consciência delas, muitas vezes, pode até levar a impasses e paralisação da própria pesquisa. Envolvem repensar as relações entre realidade e representação, memória e história, veracidade e imaginação, versão e factualidade, unidade conceitual do testemunho e pluralidade de fontes, acima de tudo, o caráter intrinsecamente político do testemunho e seu problema.

Começando pela questão da necessidade de serem analisadas fontes múltiplas e não exclusivamente fontes orais, não é de estranhar que todas as fontes históricas se constituam em unidades documentais regidas por exclusiva lógica interna. A crítica documental minuciosa, tão a gosto da escola

* Professora livre-docente do Programa de Pós-Graduação de História Social da Faculdade de Filosofia, Letras e Ciências Humanas da Universidade de São Paulo (USP). 
metódica, que instituiu procedimentos da crítica interna e externa com a preocupação de garantir à historiografia critérios de veracidade, coesão e confirmação de dados dentro de um discurso historiográfico coerente, cronológico e explicativo, contribuiu para o primeiro grande avanço da metodologia histórica.

A partir de meados do século XX, correspondendo a profundas transformações da nova fase do capitalismo, a perspectiva metódica passou por crivos sucessivos que contestaram seus princípios epistemológicos, propondo outras temáticas e métodos que resultaram em leituras subjetivas das fontes usuais do historiador. Sucederam-se modificações literárias e temáticas vinculadas a uma concepção de história cultural abrangente que substituiu a racionalidade excessiva e a linearidade explicativa por outros paradigmas, entre eles a identificação da história com memória.

Desde a década de 1960 do século passado, as ciências exatas e humanas debatem um tema de profundo significado para o desenvolvimento do conhecimento: a crise dos paradigmas. Agnes Heller (1999) atribui às transformações da modernidade, processo que considera em curso, mutações tão profundas que estão alterando a forma de viver e de pensar mesmo nos países que começam a modernizar-se. $\mathrm{Na}$ sua maneira de interpretar a contemporaneidade, considera a substituição dos padrões éticos pelo interesse próprio um dos mais graves prejuízos a ser enfrentado. Embora seu pensamento apresente alguns pontos discutíveis, é irrefutável que alguns paradigmas das ciências foram abandonados e substituídos.

Em história, por exemplo, o estruturalismo foi responsável por propostas inovadoras dirigidas contra as concepções do materialismo dialético e as da escola metódica. Embora criticado pelos autores da Nova História francesa que incorporaram vários de seus postulados e pelos historiadores marxistas ingleses contemporâneos, alguns de seus paradigmas tiveram ampla divulgação: a negação da ideia de totalidade; a busca da verdade não deve nortear as pesquisas, pois ela não existe em termos absolutos; os acontecimentos são fatos construídos independentemente uns dos outros, o que resulta na exclusão da ideia de processo e estrutura; o real é inerente à sua representação. $\mathrm{O}$ conjunto desses paradigmas está longe de ser aceito pela maioria dos historiadores. ${ }^{1}$

1 Ver texto de apresentação do livro História, metodologia, memória (Montenegro, 2010, p. 7-12). 
Os exageros dessa interpretação dominante, pelo menos há meio século, suscitaram atualmente a indignação de Beatriz Sarlo:

O que trato de apresentar em meu livro [Tiempo pasado] é que uma reconstrução feita somente a partir da memória é insuficiente e provavelmente muito menos rica do que uma reconstrução que trabalhe com todas as fontes possíveis: não só testemunhos, mas também as fontes escritas, que são indispensáveis para a compreensão do movimento das idéias na história. A memória não só está ancorada na primeira pessoa mas também permanece carregada de todos os traços de subjetividade. [...] Eu não confio mais na memória do que nas informações jornalísticas, nos programas políticos, nos livros [...]. (Mota, 2006).

Não resta dúvida que a história oral, a partir dos anos 1970, quebrou uma série de paradigmas anteriores e continua em fase de construir seus próprios. Metodologia baseada em testemunhos, aprimora suas técnicas defendendo um campo próprio e interdisciplinar apesar de estar incorporada na maioria dos trabalhos sobre o tempo presente e a história imediata. Tarefa em grande parte política, onde a conquista de territórios institucionais exclusivos exige constante empenho.

\section{Testemunhos}

A intenção desta reflexão é levantar alguns problemas que envolvem as relações entre os diferentes tipos de testemunho e o estatuto metodológico da história oral. Dentro dos limites do presente texto, foram priorizados como exemplo dois acontecimentos de importância política cujos envolvidos tiveram seus testemunhos gravados, transcritos e publicados; são eles: o julgamento pelo Estado de Israel, em 1961, do oficial da SS Adolf Eichmann por crimes cometidos contra o povo judeu, durante a Segunda Guerra Mundial; o julgamento pelo Estado francês, em 2001, do general Paul Aussaresses, acusado de fazer apologia de crimes de guerra em seu livro Services spéciaux - Algérie 1955-1957, ${ }^{2}$ no qual relatou torturas infligidas pela unidade de

2 Ver Aussaresses (2001). 
paraquedistas que comandou, cometidas na guerra de libertação da Argélia. Eichmann foi condenado à morte e Aussaresses também condenado, embora a pena tenha sido prescrita por tempo decorrido, perdendo, contudo, a Légion d'honneur.

Sobre o julgamento de Eichmann, Hannah Arendt fez cobertura para a revista The New Yorker ${ }^{3}$ e, posteriormente, em 1963, publicou o livro Eichmann em Jerusalém: um relato sobre a banalidade do mal (Arendt, 2000), ${ }^{4}$ que pode ser considerado seu próprio testemunho sobre o julgamento. Aussaresses, inconformado com a condenação, publicou mais dois livros, intermediados por perguntas formuladas por Deniau e Sultan. ${ }^{5}$ Além dos livros, passou a conceder diversas entrevistas para programas televisivos, sendo uma delas, originalmente da série de Patrik Rotman $O$ inimigo intimo: violência na Argélia, reproduzida como extra do DVD do famoso filme $A$ batalha de Argel (1966), de Gillo Pontecorvo, distribuído no Brasil. ${ }^{6}$

Essas personagens tornaram-se notórias e sucederam-se documentários televisivos, artigos de revistas e livros que multiplicaram esses acontecimentos em novas opiniões e relatos, criando para o historiador problemas relativos à factualidade e à opinião. $\mathrm{O}$ clamor público foi intenso, sucederam-se inúmeros depoimentos sobre a ação dos réus nas mídias.

A conjuntura internacional era dominada pela Guerra Fria, que informava o ritmo da política - independência da Argélia, ditaduras na América Latina, início das Brigadas Vermelhas na Itália e perseguições do macartismo nos Estados Unidos ${ }^{7}$ - preparando os Estados internamente para a virada à direita dos governos europeus e americanos para o enfrentamento do inimigo externo corporificado no medo do comunismo.

3 O relato foi publicado na revista entre fevereiro e março de 1963.

4 Eichmann in Jerusalem: a report on the banality of evil (Arendt, 1963). A edição usada no presente texto tem tradução José Rubens Siqueira, baseada na edição de 1964.

5 Ver Aussaresses $(2004,2008)$.

6 Ver Aussaresses (2002).

7 Em inglês $M c$ Carthyism, campanha anticomunista radical liderada pelo senador Joseph Raymond McCarthy, quando presidente do Senate's Government Operations Committee, em conformidade com a Doutrina Truman de 1947. No cenário internacional, os americanos e aliados ocidentais organizaram o Plano Marshall em 1947 e a Organização do Tratado do Atlântico Norte (Otan) em 1949. Consideravam que as ameaças de possível avanço comunista vinham da vitória da Revolução Chinesa em 1949, do Pacto de Varsóvia em 1949 - liderado pela União Soviética - e da explosão da primeira bomba atômica soviética em 1949. 
O caleidoscópio de testemunhos põe o pesquisador frente à complexa empreitada de construir um discurso historiográfico. A natureza dos documentos necessita ser definida. São versões de dados de realidade, invenções, representações, informações privilegiadas? Há tensões internas nas possíveis respostas que, no mínimo, devem considerar três instâncias teórico-metodológicas: a dos depoentes, a dos interrogadores ou entrevistadores e a do público.

Ao decidir revelar suas rememorações, o depoente concebe o conteúdo e a forma da linguagem, tendo em vista determinadas finalidades ocultas ou evidentes e julga seu testemunho verdadeiro, mesmo que deliberadamente mascare o vivido. $\mathrm{O}$ entrevistador (cientista social, repórter, advogado, promotor e juiz) tem um plano traçado que deverá ser preenchido pelo testemunho obtido, seja usando interrogatório ou livre diálogo, é dono de um conhecimento específico e conjuntural que, eventualmente, pode o depoente não possuir. Domina técnicas e métodos, que precisam ser assegurados para a aceitação do público a que seu trabalho se destina. Em geral, não há muitas coincidências entre a visão de mundo do entrevistado e do entrevistador emprestando o famoso termo de Georg Lucáks -, e observam-se nos resultados finais esses desvios de rotas.

Testemunhos, escritos ou orais, destinados à divulgação na mídia, como os que se seguiram aos julgamentos, continham compromissos preestabelecidos com a consciência individual e a indústria cultural.

A interação com as exigências do mercado introduzem elementos de apelo aos sentidos, como se nota na entrevista de Aussaresses publicada, em 2008 na Folha de S. Paulo, com a seguinte manchete: "A tortura se justifica quando pode evitar a morte de inocentes. General francês que ensinou tortura a militares brasileiros confirma atuação do país em golpe contra Salvador Allende". ${ }^{8}$ Essa matéria foi motivada pela publicação do último livro de Aussaresses (2008), Je n'ai pas tout dit: ultimes révélations au service de la France. Nele, o general relata ter sido nos anos 1960 instrutor de paraquedistas da infantaria americana em Fort Benning na Geórgia, e no Fort Bragg na Carolina do Norte, na qualidade de instrutor das Forças Especiais do exército americano, envolvido com as guerrilhas do Vietnã. Nesses locais de treinamento antiterrorista conheceu vários oficiais da América do Sul, inclusive 
brasileiros. Foi adido militar da embaixada francesa no Brasil de 1973 a 1975; fazia trabalho de informação e intermediava a venda de aviões Mirage, fabricados pela Société Dassault. Ministrou cursos de interrogatório e informação a oficiais no Centro de Instrução de Guerra na Selva, em Manaus. Confirma que o governo do general Garrastazu Médici forneceu armas e avióes para o golpe militar contra Allende no Chile (11/09/1973) e diversos fatos da conhecida operação Condor. Nessa ocasião tornou-se amigo do general João Baptista Figueiredo, chefe do Serviço Nacional de Informações (SNI), do delegado Sérgio Fleury e de Umberto Gordon, chefe das forças especiais do Chile - Dina, serviço secreto do governo do general Pinochet. Na entrevista foram publicados exclusivamente trechos referentes ao Brasil e à América Latina, porque nesses países o processo de acerto de contas com a ditadura estava em curso.

Podem ser identificados vários outros modelos de testemunhos em torno dos julgamentos de Eichmann e Aussaresses: textos de Hannah Arendt, documentários e entrevistas dirigidas e realizadas por Patrik Rotman, o filme de Gillo Pontecorvo, os entrevistadores de Aussaresses, Deniau e Sultan, pessoas mencionadas nas memórias, testemunhas dos julgamentos, militares franceses, além de advogados, juízes, promotores, jornalistas e historiadores. Assediados pela mídia, muitos testemunharam.

Testemunhar não é apenas dizer o que viu ou ouviu, mas é também a construção de um discurso sobre o factual. Tome-se o caso de Hannah Arendt. Seu livro Eichmann em Jerusalém foi alvo de acerbas críticas por ter a autora relatado o que ouviu sobre os conselhos judaicos - representantes da comunidade junto às autoridades alemãs durante a exportação e a solução final. O subtítulo de seu trabalho - a banalidade do mal - foi mal interpretado, em grosseira distorção do sentido que desejou dar a essas palavras, que se referiam à forma burocrática encontrada pelo réu para justificar suas atitudes, como mero executor de ordens. A respeito, diz Arendt (2000, p. 305-307):

Mesmo antes de sua publicação, este livro se tornou foco de controvérsia e objeto de uma campanha organizada. Nada mais natural que a campanha, levada a cabo por bem conhecidos meios de fabricação de imagem e manipulação de opinião, tenha tido muito mais atenção que a controvérsia, de forma que esta última foi um tanto engolida e sufocada pelo barulho artificial da primeira. [...] Tudo isso foi possível por causa do clamor centralizado na "imagem" de um livro que nunca foi escrito e que supostamente versava sobre assuntos que muitas vezes não só não foram mencionados por mim, mas que nunca me ocorreram antes. [...] Desde que o papel da 
liderança judaica veio à baila no julgamento, e desde que eu o comentei, foi inevitável que ele fosse discutido. Isso, em minha opinião, era uma questão séria, mas o debate pouco contribuiu para seu esclarecimento.

Depoimentos desdobraram-se em discussões que seguiram outros espaços de interesse, afastando-se dos episódios do próprio julgamento. Era o momento de acerto de contas de um passado não digerido, cujo legado restringia-se a atrocidades. Julgava-se então a Alemanha e o nazismo.

Aussaresses, como Eichmann, também se declarou um militar patriota cumpridor de ordens. Deixou claro que criou estratégias para identificar os "terroristas argelinos", que incluíam torturas e assassinatos, de conhecimento do supremo comando e do governo francês. Concordou com a veracidade do filme de Gillo Pontecorvo A batalha de Argel, confirmando todos os episódios nos quais foi participante e chefe da repressão. Isso foi suficiente para reavivar na França uma revisão do passado abrangendo o colaboracionismo, os escândalos do governo de Vichy, a derrota da França - não assumida por De Gaulle e seus seguidores -, os contatos dos governos democráticos com informantes nazistas e, principalmente, os episódios da guerra suja, incluindo a Indochina e a Argélia; julgava-se a violência da luta colonialista. Significativo foi um telefonema do general Bigeard enraivecido com a longa entrevista de Aussaresses ao jornal Le Monde, começando por dizer "o que aconteceu para que você abrisse a boca?” (Aussaresses, 2008, p. 13, tradução minha).

Há considerações de caráter militar que interferiram diretamente nos testemunhos. Segredos dos serviços secretos da Alemanha e da França - SS e Action - foram revelados, provocando reprovação da parte de militares que tinham no silêncio um código de honra e segurança. Dentro da ética corporativa os réus foram considerados traidores; teriam sido apreciados se assumissem a culpa por inteiro, como se pode constatar em diversos pronunciamentos de militares, no caso de Aussaresses, e panfletos anônimos, no caso de Eichmann.

Enquanto Eichmann via-se como um funcionário competente e injustiçado por seus superiores por não ter sido promovido, Aussaresses pensava ter evitado massacres de franceses, tanto na Argélia quanto na França, agindo para evitar um mal maior. Política e moral, fronteiras da ação individual, os réus foram questionados insistentemente: por que não se recusaram a agir contra os princípios básicos de humanidade?

Os testemunhos dos réus tocavam em questões morais importantes como o crime por razões de Estado, conceito compreendido e por eles 
manipulado, pois, apesar de não negarem ter praticado as ações consideradas criminosas pelo tribunal, organizaram seus discursos justificando seus atos pelo interesse do Estado. Sobre esse assunto pronunciou-se Hannah Arendt (1972, p. 293-294), no livro Entre o passado e o futuro:

Sem dúvida, os segredos de Estado sempre existiram; todo governo precisa classificar determinadas informações, subtraí-las da percepção pública, e os que revelam segredos autênticos foram sempre tratados como traidores. [...] O que parece ainda mais perturbador é que, na medida em que as verdades factuais inoportunas são toleradas nos países livres, amiúde elas são, de modo consciente ou inconsciente, transformadas em opinióes - como se o fato do apoio da Alemanha a Hitler, ou o colapso da França ante as forças alemães em 1940, ou a política do Vaticano durante a Segunda Guerra Mundial não fossem questão de registro histórico e sim uma questão de opinião, visto que tais verdades factuais se relacionam com problemas de imediata relevância política, a que há mais coisas em jogo do que a tensão, talvez inevitável, entre dois modos de vida dentro do quadro de referência de uma realidade comum e comumente reconhecida. $\mathrm{O}$ que aqui se acha em jogo é essa mesma realidade comum e factual, e isso é com efeito um problema político de primeiro plano. [...] Pode ser compensador reabrir a antiga e aparente obsoleta questão da verdade versus opinião.

A leitura da rica enumeração de fontes utilizadas por Hannah Arendt (2000, p. 303) em seu livro Eichmann em Jerusalém desperta a atenção para diversas dificuldades que encontrou, entre elas: "A língua da corte era o hebraico; as matérias fornecidas à imprensa eram, dizia-se, 'uma transcrição não editada e não revisada da tradução simultânea', que 'não devia ser considerada estilisticamente perfeita e isenta de erros linguísticos."

Muitos dos presentes - depoentes, advogados, o próprio réu e o público - não entendiam o discurso do tribunal e utilizavam fones de ouvido, com tradução simultânea. O julgamento foi em grande parte gravado, foram necessários tradutores para o inglês, francês e alemão, e transcrições foram distribuídas à imprensa.

Compreendendo todas as dificuldades da produção de tal material, semelhantes às dos oralistas contemporâneos, muito se valeu a autora de um manuscrito de 70 páginas escrito pelo próprio Eichmann. Utilizou também vasto material da imprensa e bibliografia específica. Seu trabalho com fontes 
orais e escritas é um exemplo de como é possível produzir um jornalismo de alto nível quando são usadas metodologias das ciências históricas, evidenciando semelhanças entre interrogatórios judiciais e depoimentos provocados por pesquisadores e, acima de tudo, a imprescindibilidade da interpretação para dar sentido à dispersão das fontes.

Muito tem sido escrito sobre testemunhos e sua veracidade. ${ }^{9}$ Para historiadores sempre foi um procedimento usual analisar o alcance de suas fontes, mas, atualmente, impõem-se novas apreciações sobre a incorporação do testemunho na escrita da história oral.

Longe de chegar a um consenso, avulta entre inúmeros debates a questão primordial da verdade do testemunho, geralmente confundida com a epistemologia da história. No discurso historiográfico o relativismo do compromisso com a verdade parece ter tomado um espaço excessivo, tudo depende de meias verdades, da opinião e de circunstâncias específicas. Não se ousa usar a palavra verdade sem colocá-la entre aspas. A propósito, cabe lembrar conhecido diálogo de Clemenceau com um diplomata, que discorria longamente sobre o equívoco em culpar exclusivamente a Alemanha pelo desencadear da Guerra. Cansado, o chanceler teria respondido: "O senhor tem muitos argumentos, só não pode dizer que foi a Bélgica que invadiu a Alemanha."

No âmago da controvérsia, convém pensar na advertência de Hannah Arendt (1972, p. 295-296):

[...] a verdade factual informa o pensamento político exatamente como a verdade racional informa a especulação filosófica. Mas os fatos realmente existem independentes de opinião e interpretação? [...] Sem dúvida, esta e muitas outras perplexidades inerentes às ciências históricas são reais, mas não constituem argumento contra a existência da matéria factual, e tampouco podem servir como uma justificação para apagar as linhas divisórias entre fato, opinião e interpretação ou como uma desculpa para o historiador manipular os fatos a seu bel-prazer.

Enquanto se encontram tantos empecilhos em falar da factualidade, usa-se com a maior liberalidade os testemunhos como expressão de verdade

9 Ver Amado e Ferreira (1996), Esperança (2006), Ferreira (1994), Gagnebin (1997), Gomes (2004), Hartog (2001), Koselleck (2002), Lins Caldas (1999), Medina (1990), Montenegro (2010), Olson e Torrance (1997), Prost (1996), Ricoeur (2000), Rioux (1999) e Rollemberg (1994). 
e autoridade. É inegável a integridade conceitual que o testemunho tem em si. Para a sociologia, como bem ressaltam Pollak e Heinich (1986), seu traço mais característico vincula-se à construção de identidades variáveis segundo as finalidades a que se destinam. Extrapolando o limite da vida privada, o depoimento adquire seu significado coletivo desde que tenha como referencial a mesma factualidade comungada pelos grupos sociais a que pertence; com toda propriedade, Maurice Halbwachs (1965) foi o formulador dessa interpretação metodológica.

É sobejamente conhecido o fenômeno da produção de biografias e depoimentos que assolaram a cultura ocidental a partir da Segunda Guerra Mundial. Novas mídias e recursos tecnológicos permitiram a proliferação de testemunhos de atrocidades, tema explorado por Marcio Seligmann Silva (2005) no artigo "Testemunho e a política da memória: o tempo depois das catástrofes". Nesse texto, o autor reflete sobre a "literatura de testemunho", afirmando:

O conceito de testemunho concentra em si uma série de questões que sempre polarizaram a reflexão sobre a literatura: antes de qualquer coisa, ele põe em questão as fronteiras entre o literário, o fictício e o descritivo. E mais: o testemunho aporta uma ética da escritura. Partindo-se do pressuposto, hoje em dia banal, que não existe "grau zero da escritura", ou seja, a literatura está ali onde o sujeito se manifesta na narrativa, não podemos deixar de reconhecer que, por outro lado, o histórico que está na base do testemunho exige uma visão "referencial", que não reduza o "real" à sua "ficção" literária. Ou seja, o testemunho impõe uma crítica da postura que reduz o mundo ao verbo, assim como solicita uma reflexão sobre os limites e modos de representação. (Silva, 2005, p. 85).

Como é necessário atentar para a especificidade do discurso literário igualmente pressupõem-se condutas metodológicas próprias dos audiovisuais, mesmo porque já foram mencionadas entrevistas divulgadas pela mídia. Nesse caso, Marcos Napolitano (2006, p. 236) discorda daqueles que vêm tanto nos documentários exibidos pelo cinema ou pela televisão como nos registros sonoros testemunhos diretos e objetivos da história, enquanto consideram filmes de ficção, teledramaturgia, canções e peças musicais fontes de absoluta subjetividade, como afirma o autor: "A questão, no entanto, é perceber as fontes audiovisuais e musicais em suas estruturas internas de linguagem e seus mecanismos de representação da realidade, a partir de seus 
códigos internos." Assinala que um bom caminho é o de articular a linguagem técnico-estética das fontes audiovisuais e musicais (ou seja, seus códigos internos de funcionamento) e as representações da realidade histórica ou social nela contidas (isto é, o seu conteúdo narrativo propriamente dito).

\section{À guisa de epílogo}

São tantas as maneiras próprias de ver e interpretar os testemunhos no interior de cada disciplina que comprometem ou, pelo menos, tornam dificilmente praticável o emprego de uma postura multidisciplinar na escrita da história oral. Há complementaridade nas diferentes metodologias, mas, para se traduzirem num discurso coerente, exigiriam o domínio de muitas habilidades. Os obstáculos têm superado os ganhos obtidos. Apesar de, na maioria dos trabalhos de história oral, ter prevalecido o autoritarismo do testemunho e a perspectiva da formação específica do pesquisador, em publicações recentes se vislumbram, de forma nítida, maior cuidado com: o sentido político e metafórico da linguagem, o entrelaçamento dos conteúdos de um conjunto de narrativas e até a possibilidade de existência de insuperável incompreensão entre entrevistador e entrevistado (Guimarães Neto, 2008; Siqueira, 2008).

Não se pode negar que exaustivas citações de testemunhos têm sido evitadas em obras atuais, recortes significativos são feitos e, em grande parte, poder-se-ia talvez afirmar que o discurso do historiador venceu o do depoente. A passagem do tempo não pode ser sempre responsabilizada pelas alterações que as rememorações introduzem na narrativa do vivido. Um tempo acelerado, pleno de acontecimentos diários repletos de significados, é sempre para alguns o tempo presente, aquele que é história e não memória, onde a luta política ainda persiste, este é um dos pilares fundamentais onde se assenta a identidade dos testemunhos. No entanto, há aqueles para quem a história perdeu seu conteúdo referencial, transformando-se em memória dolorosa daquilo "que nem é bom lembrar". Usam de complacência como ao contar um pecado cometido, justificado pela pouca idade do pecador. A situação anteriormente rica de historicidade transmuda-se em uma soma de equívocos compreensíveis pelos sucessos posteriores, sugerindo-nos a indagação: se o futuro explica o passado e vice-versa, o presente seria o momento da ação e da política ${ }^{10}$

10 Ver Janotti (2001). 


\section{Referências}

AMADO, J.; FERREIRA, M. de M. (Coord.). Usos e abusos da história oral. Rio de Janeiro: Editora da Fundação Getúlio Vargas, 1996.

ARENDT, H. Eichmann in Jerusalem: a report on the banality of evil. London: Penguin, 1963.

. Eichmann em Jerusalém: um relato sobre a banalidade do mal. Tradução José Rubens Siqueira (baseado na edição de 1964). 2. ed. São Paulo: Companhia das Letras, 2000.

Entre o passado e o futuro. Tradução Mauro W. Barbosa de Almeida. 2. ed. São Paulo: Perspectiva, 1972. (Série Debates).

AUSSARESSES, P. Services spéciaux - Algérie 1955-1957. Paris: Perrin, 2001.

. Entrevista. In: O INIMIGO íntimo: violência na Argélia (episódio Estados armados). Série para TV. Direção de Patrik Rotman. 2002. (28 min). [Extras do filme A BATALHA de Argel. Direção de Gillo Pontecorvo. Argel: Casbah Films, Argel, 1966. Distribuição: Videofilmes Produções Artísticas, Rio de Janeiro, 2005. 1 DVD (aprox. 121 min.), $\mathrm{PB}$, legendado em português].

. Pour la France: service spéciaux. 1942-1954. Paris: Éditions du Rocher, 2004.

. Je n'ai pas tout dit: ultimes révélations au service de la France. Entretiens avec JeanCharles Deniau et Madeleine Sultan. Paris: Éditions du Rocher, 2008.

ESPERANÇA, C. G. Testemunhas ou fontes: relações e desencontros entre jornalistas e historiadores. Questão, Porto Alegre, v. 12, n. 2, p. 235-251, jun./dez. 2006.

FERREIRA, M. de M. (Org.). História oral e multidisciplinaridade. Rio de Janeiro: Diadorim, 1994.

GAGNEBIN, J. M. Sete aulas sobre linguagem, memória e história. Rio de Janeiro: Imago, 1997.

GOMES, A. de C. (Org.). Escrita de si, escrita da história. Rio de Janeiro: FGV, 2004.

GUIMARÃES NETO, R. B. Espaços e tempos entrecruzados na história: práticas de pesquisa e escrita. In: MONTENEGRO, A. T. et. al. (Org.). História: cultura e sentimento: outras histórias do Brasil. Recife: Ed. Universitária da UFPE; Cuiabá: Ed. da UFMT, 2008. p. 135-166.

HALBWACHS, M. Les cadres sociaux de la mémoire. Paris: Felix Alcan, 1965. 
HARTOG, F. A testemunha e o historiador. In: PESAVENTO, S. (Org.). Fronteiras do Milênio. Porto Alegre: Editora da Universidade/UFRGS, 2001. p. 11-41.

HELLER, A. Uma crise global da civilização: os desafios futuros. In: HELLER, A. et al. A crise dos paradigmas em ciências sociais e os desafios para o século XXI. Rio de Janeiro: Contraponto, 1999. p. 13-32.

JANOTTI, M. L. M. Problemas metodológicos: depoimentos e repressão. Caderno CERU, São Paulo: Humanitas/FFLCH, n. 12, p. 31-51, 2001.

KOSELLECK, R. Historia y hermenéutica. Barcelona: Paidós, 2002.

LINS CALDAS, A. Oralidade, texto e história: para ler a história oral. São Paulo: Loyola, 1999.

MEDINA, C. de A. Entrevista: o diálogo possível. São Paulo: Ática, 1990.

MONTENEGRO, A. T. História, metodologia, memória. São Paulo: Contexto, 2010.

MOTA, D. Chega de subjetividade: entrevista de Beatriz Sarlo. Trópico, São Paulo, 29 abr. 2006. Seção História. Disponível em: <http://pphp.uol.com.br/tropico/html/ textos/2735,1.shl>. Acesso em: 10 abr. 2010.

NAPOLITANO, M. Fontes audiovisuais: a história depois do papel. In: PINSKY, C. B. (Org.). Fontes históricas. 2. ed. São Paulo: Contexto, 2006. p. 235-290.

OLSON, D.; TORRANCE, N. (Org.). Cultura escrita e oralidade. 2. ed. São Paulo: Ática, 1997.

POLLAK, M.; HEINICH, N. Le témoignage. Actes de la Recherche en Sciences Sociales, n. 62-63, p. 3-29, 1986.

PLON, L. D. A tortura se justifica quando pode evitar a morte de inocentes: entrevista com General Paul Aussaresses. Folha de S. Paulo, São Paulo, p. A 10, 4 maio 2008.

PROST, A. Histoire, verités, méthodes: des structures argumentatives de l'histoire. Le Débat, Paris, n. 92, p. 127-140, nov./déc. 1996.

RICOEUR, P. L'ecriture de l'histoire et la représentation du passé. Annales HSS, Paris, n. 4, p. 731-747, juil./oct. 2000.

RIOUX, J.-P. Entre história e jornalismo. In: CHAUVEAU, A.; TÉTART, P. (Org). Questóes para a história do presente. Bauru: Edusc, 1999. p. 119-126.

ROLLEMBERG, D. (Org.). Que história éessa?: novos temas e novos problemas em história. Rio de Janeiro: Relume-Dumará, 1994. 
SILVA, M. S. Testemunho e a política da memória: o tempo depois das catástrofes. Projeto História, São Paulo: PUC, n. 30, p. 71-98, jun. 2005. [Publicado em 2006].

SIQUEIRA, A. J. As representações do corpo na Idade Média. In: MONTENEGRO, A. T. et. al. (Org.). História: cultura e sentimento: outras histórias do Brasil. Recife: Ed. Universitária da UFPE; Cuiabá: Ed. da UFMT, 2008. p. 95-106.

Resumo: Mesmo conhecendo todos os procedimentos usuais que envolvem a produção de fontes orais, registradas em vídeos ou provenientes de entrevistas, e dominando a arte da edição de textos, ainda assim o pesquisador encontra-se frente à empreitada mais intricada: construir um discurso historiográfico. O objetivo deste artigo é levantar os principais problemas que envolvem as relações entre os diferentes tipos de testemunho e o estatuto metodológico da história oral. Dar-se-á especial atenção a depoimentos colhidos com finalidades jornalísticas e jurídicas como os de Hannah Arendt, presente no livro Eichmann em Jerusalém (1963), e os de Paul Aussaresses em Services spéciaux - Algérie 1955-1957 (2001).

Palavras-chave: história oral, testemunhos orais, escrita histórica, controvérsias metodológicas.

The incorporation of the oral testimony in the writing historical: difficulties and controversies

\begin{abstract}
Same knowing all the usual procedures that involve the production of oral sources, registered in videos or coming of interviews, and dominating the art of the edition of texts, nevertheless the researcher meets front to the most intricate taskwork: to build a historical speech. The objective of this article is to lift the principal problems that involve the relationships between the different testimony types and the methodological statute of the oral history. It will feel special attention to depositions picked with journalistic and juridical purposes: Eichmann in Jerusalem by Hannah Arendt (1963) and Services spéciaux - Algérie 1955-1957 (2001) by Paul Aussaresses.
\end{abstract}

Keywords: oral history, oral testimonies, historical writing, methodological controversies.

Recebido em 02/10/2010

Aprovado em 15/12/2010 